\title{
Semantic Congruence Accelerates the Onset of the Neural Signals of Successful Memory Encoding
}

\author{
Pau A. Packard, ${ }^{1,2,3}$ Antoni Rodríguez-Fornells, ${ }^{1,2,4}$ @Nico Bunzeck, ${ }^{3,5}$ @Berta Nicolás, ${ }^{1,2}$ @Ruth de Diego-Balaguer, ${ }^{1,2,4,6}$ \\ and Lluís Fuentemilla ${ }^{1,2,6}$ \\ ${ }^{1}$ Cognition and Brain Plasticity Group (Bellvitge Biomedical Research Institute) IDIBELL, L'Hospitalet de Llobregat, Barcelona 08908, Spain, ${ }^{2}$ Department \\ of Cognition, Development and Educational Psychology, University of Barcelona, L'Hospitalet de Llobregat, Barcelona 08907, Spain, ${ }^{3}$ Department of \\ Psychology, University of Lübeck, 23562 Lübeck, Germany, ${ }^{4}$ Institució Catalana de Recerca i Estudis Avançats, 08010 Barcelona, Spain, ${ }^{5}$ Department of \\ Systems Neuroscience, University Medical Center Hamburg-Eppendorf, 20246 Hamburg, Germany, and ${ }^{6}$ Institute of Neurosciences, University of \\ Barcelona, Barcelona 08193, Spain
}

As the stream of experience unfolds, our memory system rapidly transforms current inputs into long-lasting meaningful memories. A putative neural mechanism that strongly influences how input elements are transformed into meaningful memory codes relies on the ability to integrate them with existing structures of knowledge or schemas. However, it is not yet clear whether schema-related integration neural mechanisms occur during online encoding. In the current investigation, we examined the encoding-dependent nature of this phenomenon in humans. We showed that actively integrating words with congruent semantic information provided by a category cue enhances memory for words and increases false recall. The memory effect of such active integration with congruent information was robust, even with an interference task occurring right after each encoding word list. In addition, via electroencephalography, we show in 2 separate studies that the onset of the neural signals of successful encoding appeared early ( $\sim 400$ ms) during the encoding of congruent words. That the neural signals of successful encoding of congruent and incongruent information followed similarly $\sim 200$ ms later suggests that this earlier neural response contributed to memory formation. We propose that the encoding of events that are congruent with readily available contextual semantics can trigger an accelerated onset of the neural mechanisms, supporting the integration of semantic information with the event input. This faster onset would result in a long-lasting and meaningful memory trace for the event but, at the same time, make it difficult to distinguish it from plausible but never encoded events (i.e., related false memories).

Key words: congruence; EEG; episodic memory; schemas; successful encoding

Significance Statement

Conceptual or schema congruence has a strong influence on long-term memory. However, the question of whether schema-related integration neural mechanisms occur during online encoding has yet to be clarified. We investigated the neural mechanisms reflecting how the active integration of words with congruent semantic categories enhances memory for words and increases false recall of semantically related words. We analyzed event-related potentials during encoding and showed that the onset of the neural signals of successful encoding appeared early $(\sim 400 \mathrm{~ms})$ during the encoding of congruent words. Our findings indicate that congruent events can trigger an accelerated onset of neural encoding mechanisms supporting the integration of semantic information with the event input.

\section{Introduction}

As the stream of experience unfolds, our memory system rapidly transforms current inputs into long-lasting meaningful memories. Because of the ongoing nature of our experience, many of the factors that contribute to this possibility depend on brain mechanisms that take place during the encoding itself (Tulving, 2002). A putative neural mechanism that strongly influences how input elements are transformed into a memory code requires integrat-

The authors declare no competing financial interests.

Correspondence should be addressed to Pau A. Packard, Department of Psychology, University of Lübeck, Maria-Goeppert-Straße 9a, 23562 Lübeck, Gebäude MFC 8, 2. OG, Raum 8, Germany. E-mail: pau.packard@uni-luebeck.de.

DOI:10.1523/JNEUROSCI.1622-16.2016

Copyright $\odot 2017$ the authors $\quad 0270-6474 / 17 / 370291-11 \$ 15.00 / 0$ 
ing input with existing structures of knowledge or schemas (Tse et al., 2011). Information that is congruent with prior knowledge is often found to be better remembered than incongruent information (Staresina et al., 2009; Atienza et al., 2011; van Kesteren et al., 2014; Bein et al., 2015). However, congruency effects can also be disadvantageous and lead to altered recall (Bartlett and Burt, 1933) or false recall (Roediger and McDermott, 1995) of plausible semantically related but never experienced events during memory encoding. These seemingly counterintuitive effects have been explained in terms of a rapid assimilation process that may underlie the formation and storage of congruent memories. Activation of relevant prior knowledge would help boost new memories and store them more schematically because they can be directly related to previously learned association networks (van Kesteren et al., 2012). Thus, given the unfolding nature of our experience, an important question to be addressed is whether schema-related memory integration neural mechanisms take place during the online encoding of congruent information.

To achieve this, the work reported here includes 4 experiments combining data from behavioral measures as well as from event-related potentials (ERPs). We used ERPs here because they allow for the assessment of the rapid neural activity that is predictive of successful memory encoding (Paller and Wagner, 2002). Indeed, successful encoding is typically accompanied by an electrophysiological correlate, the difference due to memory (DM) effect, appearing $\sim 600 \mathrm{~ms}$ after a successfully encoded event (Sanquist et al., 1980; Johnson, 1995; Rugg and Coles, 1996; Paller and Gross, 1998; Paller and Wagner, 2002). The DM effect is thought to chiefly reflect processes of memory formation (Kim, 2011; Cohen et al., 2015). The fact that it appears later than ERPs associated with semantic processing, such as the N400, which appears 300-500 ms after initial encoding (Kutas and Federmeier, 2011), suggests that it may be affected by the inputs resulting from semantic computations of the event. Intracortical EEG recordings also showed such sequential activity at different medial temporal lobe (MTL) regions (Fernández et al., 1999, 2002). Memory formation was associated with interrelated ERP differences within the rhinal cortex and the hippocampus, which arose after $\sim 300$ and $500 \mathrm{~ms}$, respectively. These findings also suggest that declarative memory formation is dissociable into subprocesses and sequentially organized within the MTL. Thus, the timing and nature of the encoding operations may depend on the results of such semantic computations, namely, whether congruent semantic associations are quickly detected or not. Resulting congruent semantic associations could be rapidly encoded together with a trace for the event, resulting in a more complex, long-lasting, and meaningful, memory trace for the event (van Kesteren et al., 2012). Based on these observations, we predicted that the encoding of congruent events would accelerate the onset of the integration of semantic information with the event input and that this would be reflected as a neural response that would precede the appearance of a general DM effect.

To test this prediction, we used an adaptation of a word list paradigm (Craik and Tulving, 1975; Roediger and McDermott, 1995; Kim and Cabeza, 2007a) that produces a powerful congruence-related memory enhancement, and a strong tendency for false memories of semantically related lure words. Participants preactivated specific semantic memory networks corresponding to a semantic category, before studying four item word lists visually presented in a rapid stream at a rate of 250 ms/word. Thus, we predict an enhanced memory performance for words encoded in a congruent context accompanied, similarly, by higher rates of false memories.

\section{Materials and Methods}

\section{Participants}

Participants were college undergraduate students who had normal or corrected-to-normal vision and reported no history of medical, neurological or psychiatric disorders. Thirty-two students (15 female, mean \pm SD: $21.58 \pm 2.99$ years) were recruited for Experiment 1 . In addition, 21 students ( 20 female, $22.38 \pm 7.46$ years) participated in Experiment 2, 15 students ( 13 female, $22.93 \pm 6.57$ years) participated in Experiment 3, and 20 students (10 female, $23.26 \pm 2.99$ years) participated in Experiment 4.

Experimental stimuli consisted of 72 categorical 6 word lists selected from category norms (Battig and Montague, 1969; Yoon et al., 2004; Kim and Cabeza, 2007a) translated into Spanish (Goikoetxea, 2000). Each list consisted of the 6 most typical instances (e.g., cow, pig, horse, chicken, sheep, and goat) of a natural/artificial category (e.g., farm animal). In each list, the third to the sixth typical instances were used as encoding stimuli (True words); the first and the second typical instances were used as 'critical lures' (Lure words) in the test phase. Additionally, semantically unrelated words, matched in letter number, frequency, and concreteness to the category words, were used as control words (New words) in the test phase.

None of the participants had previous knowledge of the DeeseRoediger-McDermott (DRM) task (Roediger and McDermott, 1995). All participants signed informed consent, approved by the University of Barcelona Ethics Committee.

\section{Behavioral procedures}

Experiments 1-3. We used an adaptation of an experimental paradigm used in fMRI studies (Kim and Cabeza, 2007a, b), itself adapted from the DRM paradigm (Roediger and McDermott, 1995). In the paradigm used here, participants preactivate specific semantic memory networks before words are presented. Thus, the cueing of a semantic network favors the incorporation of the associated word items into a context with congruent semantic unfolding.

The study phase consisted of the presentation of 72 word lists. Participants observed the screen from a distance of $\sim 90 \mathrm{~cm}$ on a 17 inch display. Arial letter type, 18 letter size was used. Each trial started with the appearance of a fixation cross on the screen for a random duration of 2500-3500 ms. Afterward, a category name in blue appeared on a white background for $1500 \mathrm{~ms}$. In the congruent condition, the subsequent words belonged to such semantic category (Craik and Tulving, 1975). In the incongruent condition, the category name did not correspond to any subsequent item. Incongruent lists (all words were presented in Spanish) were formed by a category cue followed by a nonmatching sequence of 4 words, for example, 'planets' followed by 'residence,' 'mansion,' 'cottage,' 'apartment'; or 'continents' followed by 'carbon,' 'sulfur,' 'hydrogen,' and 'oxygen.' Congruent lists were formed by category cues followed by a matching sequence of 4 words for example, 'colors' followed by 'blue,' 'green,' 'black,' 'white'; or 'furniture' followed by 'desk,' 'sofa,' 'divan,' and 'chair.' After the cue disappeared, a fixation cross appeared for $2000 \mathrm{~ms}$. Participants were then sequentially shown the 4 subsequent words in green, each lasting $250 \mathrm{~ms}$, with no interval between them. Participants were informed that, after this first phase, there would be a memory test.

In Experiment 1, after the 4 words were shown, a display with a question mark appeared, signaling the participant to press a button on the mouse indicating whether the words were congruent (left click) or incongruent (right click) with the semantic category indicated at the beginning of the trial (we indicate words and symbols we presented on the screen with double quotation marks). The trial ended as soon as the participant responded. Participants were instructed to respond thoughtfully but without delay. In Experiment 2, we added an interference task after every word list, in half of the trials immediately before the active classification task during encoding, and in the other half, immediately after the classification task. Thus, we can interfere with possible immediate offline encoding processes occurring either before or after the clas- 
sification task (Ben-Yakov and Dudai, 2011; Ben-Yakov et al., 2013; Tambini and Davachi, 2013). The interference task consisted of simple additions and subtractions, which appeared on the screen and which participants had to solve by choosing the correct answer on the screen, similar to the longer distraction task between the encoding and test phases. Participants were told to respond as soon as possible, although no time limit was imposed. In Experiment 3, participants were instructed to 'quickly click on the mouse every time a word list is over,' that is, they promptly responded at the end of every word list but did not rate the congruency of the encoded words with the word cue. This experiment allowed us to evaluate the extent to which the memory enhancement for congruent words required an active process of memory organization during encoding (Tulving and Pearlstone, 1966; Craik and Tulving, 1975).

The conditions were counterbalanced across subjects in the following manner: half of the subjects were presented with a set of predetermined congruent and incongruent sequences, and the other half with a complementary set so that each sequence was matched with a congruent cue for half of the participants and with an incongruent cue for the other half. The order of the cues during encoding, as well as the order of the 4 words in each sequence, was in a pseudo-random order for each participant. There were 36 congruent-list trials and 36 incongruent-list trials. Together, the study phase lasted $\sim 15 \mathrm{~min}$. At the end of this phase, subjects were presented with a distraction task in which they solved simple arithmetical problems (additions and subtractions). The distraction task ensured the participants would not rehearse the words they had previously seen. The interference task lasted $\sim 5 \mathrm{~min}$, which together with the explanations for the interference task and the subsequent recognition test made for a total time interval of $\sim 10$ min between encoding and the subsequent test.

Considering that the retention interval between encoding and test was only $10 \mathrm{~min}$, the paradigm was thus designed to capture only the encoding component and not the consolidation-dependent processes underlying the schema effect. There were a total of 288 Old-word (items presented at encoding), 144 Lure-words, and 144 New-word trials. During recognition, the trials were presented in a pseudorandom order for each participant, thus directly avoiding any possible confounds due to order during the test. Words in the Old, New, and Lure categories were predetermined and the same for all participants. All words in the recognition phase were displayed in the middle of the screen, in green and same font and size as the study phase, each for $1500 \mathrm{~ms}$. Subjects were asked to identify whether the given word was presented before (old) or not (new), and indicate their level of confidence. After each word, subjects responded within $1500 \mathrm{~ms}$ by pressing one of 4 keys according to whether the word was judged to be "sure old," "unsure old," "unsure new," or "sure new." Participants were instructed to respond within $1.5 \mathrm{~s}$. The recognition phase lasted $\sim 60 \mathrm{~min}$.

Experiment 4. We designed Experiment 4 to correct for certain limitations of Experiment 1, thus clarifying certain aspects of the previous results. In Experiment 4, instead of sequences of four words, participants were presented with one word only after each cue. Thus, we avoided the possible confounds associated with the need to encode sequences of four consecutive words. Experiment 4 also allowed us to confirm the findings from Experiment 1 with a higher number of trials per condition, and as related specifically to the encoding of a single word, also resolving thus some uncertainties concerning the timing of the effects. In addition, in Experiment 4, we adopted a criterion for selecting remembered words more precise than the one used to select remembered sequences in Experiment 1 . The procedures were similar, except as noted below, the same word groups were used but here were presented differently. The words from each of the 72 semantic categories (previously organized in Experiments $1-3$ as a cue, 4 true words that were presented during encoding and at the test, and 2 lure words that were only presented during the test) were now all presented as 'True' words in separate trials, each time preceded by the corresponding semantic cue. In other words, during the study phase, all of the words associated with the 72 categories were actually presented to the participants. Finally, they were presented again in the recognition test, of which they had been informed at the beginning of the session. In this way, there were 432 separate one word encoding trials, presented mixed in random order. The timing of the trials was preserved so that, in each trial, after the appearance of the semantic cue, only one word appeared, during $250 \mathrm{~ms}$, and there was a $750 \mathrm{~ms}$ pause before the participants would give their response. Presenting only one word instead of four ensured that the effects were due specifically to a congruence effect starting with the differential encoding of the first word. Each word was presented with a congruent cue in half of the participants and with an incongruent cue with the other half of participants to counterbalance. The duration of the encoding phase was $\sim 60 \mathrm{~min}$. The test phase had a duration of $\sim 60 \mathrm{~min}$ and otherwise was the same as in the previous experiments, except that here all 432 words were presented both at encoding and test. There were no 'Lure' words presented at test.

\section{Statistical analyses of memory results}

In Experiments 1 and 3, a repeated-measures ANOVA with two withinsubjects factors: encoding condition (two levels: Congruent vs Incongruent) and the type of item at test (two levels: Trues vs Lures) was performed on the total rate of responses. For all analyses, $\alpha$ was set at 0.05 . To estimate effect sizes, we used $\eta_{\mathrm{p}}^{2}$ and Cohen's $d$ as appropriate. In the case of a participant judging a word sequence differently than we had predesigned, the sequence was still included as congruent or incongruent corresponding to its predesigned condition for the sake of simplicity. Participants subjective congruence ratings almost always coincided with our experimental design (94\%).

In Experiment 2, a similar statistical approach as in Experiments 1 and 3 was conducted. However, we additionally included the timing of the interference task into the analysis and ran the repeated-measures ANOVA with three within-subjects factors: interference timing (two levels: preclassification, postclassification), encoding condition (two levels: Congruent vs Incongruent), and test-item type (two levels: Trues vs Lures). In Experiment 4, a similar ANOVA was performed, in this case with only encoding condition (two levels: Congruent vs Incongruent) as a within-subject factor.

We ran one-sample $t$ tests on the means of each category [accuracy $=$ hit rate/(hit rate + false alarm rate)] (Urgolites et al., 2015) for both true words and related lure words [accuracy $=$ lure rate/(lure rate + false alarm rate)] for each experiment to test whether hit rates for each category (true, lures, congruent, incongruent) were greater than chance $(>0.50)$. We tested this both including all responses and separately only including high-confidence responses.

\section{Electrophysiological recordings (EEG) and analyses}

In Experiments 1 and 4, EEG was recorded (bandpass filter: $0.01-250 \mathrm{~Hz}$, notch filter at $50 \mathrm{~Hz}$ and $500 \mathrm{~Hz}$ sampling rate) using a BrainAmp amplifier from the scalp using tin electrodes mounted in an electrocap (Electro-Cap International) and located at 29 standard positions ( $\mathrm{Fp} 1 / 2$, Fz, F7/8, F3/4, FCz, Fc1/2 Fc5/6, Cz, C3/4, T3/4, Cp1/2, Cp5/6, Pz, P3/4, $\mathrm{T} 5 / 6, \mathrm{PO} 1 / 2, \mathrm{Oz})$ and at left and right mastoids. An electrode placed at the lateral outer canthus of the right eye served as an online reference. EEG was rereferenced offline to the mean of the activity of the two mastoids. Vertical eye movements were monitored with an electrode at the infraorbital ridge of the right eye. Electrode impedances were kept $<3 \mathrm{k} \Omega$. EEG was low-pass filtered offline at $<16 \mathrm{~Hz}$ for ERP analysis.

Here we used for the analysis the recordings from the three main midline electrodes (Fz, Cz, Pz) (Marco-Pallares et al., 2008; Sy et al., 2013; Vilà-Balló et al., 2015). This allows us to study the characteristics of the broadly distributed Subsequent Memory Effects (SMEs) in a direct, broad, general approach. ERPs related to semantic processing (Kutas and Federmeier, 2011) and subsequent memory (Paller and Wagner, 2002) have been thoroughly characterized, including detailed discussions of their localization and neural source. Here we were not interested in any specific differences due to laterality, for example, and the three electrodes we chose do permit a general characterization of any existing differences along the frontal-posterior axis.

ERPs during the encoding were studied by using MATLAB (The MathWorks; RRID:SCR_001622) to extract event-locked EEG epochs of $1600 \mathrm{~ms}$ starting at $100 \mathrm{~ms}$ before the presentation of the first word of the word list in Experiment 1 and 100 ms before the presentation of the word 
Table 1. Trials per condition ${ }^{a}$

\begin{tabular}{llcr}
\hline & Congruent remembered & Incongruent remembered & Forgotten \\
\hline Experiment 1 & $14.67(1.02)$ & $8.38(0.86)$ & $20.13(1.96)$ \\
Experiment 4 & $73.10(8.40)$ & $43.35(5.18)$ & $53.4(6.86)$
\end{tabular}

Data are mean (SEM) of trials for each condition included in the ERP analysis and figures. The trials included here in the forgotten column are the amount after equalizing the trials selected from the congruent and incongruent conditions. Because of the admittedly low number of trials per condition in Experiment 1 (0tten and Rugg, 2001a), when we designed Experiment 4, we made sure the number of trials was higher.

in Experiment 4. A baseline from $-100 \mathrm{~ms}$ to stimulus onset was used. ERP trials during encoding with amplifier saturation, or trials with a shift exceeding $200 \mu \mathrm{V} / \mathrm{s}$ were automatically rejected offline. In Experiment 1 , ERP trials were catalogued as 'remembered' when a minimum of 2 high confidence remembered 'True' words; otherwise, they were classified as 'Forgotten.' We chose a criterion of minimum 2 high confidence responses per sequence for several reasons. First, high confidence responses have been found empirically to be associated with higher signal-to-noise ratios for SMEs (Otten et al., 2006; Woodruff et al., 2006; Fellner et al., 2013), possibly because low-confidence responses can include a high proportion of guesses or random responses (for review, see Paller and Wagner, 2002) that are not due to the expression of an actual memory trace formed during encoding. Second, considering the false alarm rates, this criterion is well above the rate expected due to random responses. Third, this criterion was necessary to ensure an optimum ratio of accepted trials to compare the remembered and forgotten conditions (Table 1). Here, we are assuming that the congruence-related memory effect was associated with the encoding of the entire episode, including the cue and the four-word sequence following it. One subject was excluded from the analysis due to a lack of forgotten trials in this experiment. In Experiment 4, 'remembered' ERP trials included those in which participants answered correctly at test with a high confidence 'Old' response; low confidence 'Old' responses were not included in this analysis; those word trials that were incorrectly classified as 'New' in the recognition test were classified as 'Forgotten' (Otten et al., 2006). To detect reliable differences between the ERPs to remembered and forgotten lists during encoding, the ERPs from these conditions were contrasted via a repeated-measures, two-tailed cluster mass permutation test (Bullmore et al., 1999; Groppe et al., 2011) using a family-wise $\alpha$ level of 0.05. All time points between -100 and $1500 \mathrm{~ms}$ at 17 scalp electrodes (Fp1, Fp2, F3, F4, C3, C4, P3, P4, FCz, Oz, T3, T4, T5, T6, Fz, Cz, Pz) were included in the test (i.e., 27,200 total comparisons), and any electrodes within $\sim 5.44 \mathrm{~cm}$ of one another were considered spatial neighbors. Repeatedmeasures $t$ tests were performed for each comparison using the original data and 2500 random within-participant permutations of the data. For each permutation, all $t$ scores corresponding to uncorrected $p$ values of $\leq 0.05$ were formed into clusters. The sum of the $t$ scores in each cluster is the 'mass' (we indicate labels and terms we use with single quotation marks) of that cluster and the most extreme cluster mass in each of the 2501 sets of tests was recorded and used to estimate the distribution of the null hypothesis.

We then ran a repeated-measures ANOVA with the mean amplitude from time windows focused on the center of the clusters. Remembered word lists were classified according to whether during encoding they were presented in the congruent or incongruent condition. Forgotten word lists from the congruent and incongruent conditions were pooled together in the further analysis to ensure a minimum amount of trials. To equalize the number of congruent and incongruent trials in the forgotten condition, we randomly selected the same number of trials from both categories for each subject to include in the analysis. ERPs for the word lists were thus classified into three different conditions, 'Congruent Remembered,' 'Incongruent Remembered,' and 'Forgotten.' ERPs were then averaged separately for each individual and condition. Thus, the mean amplitude values were submitted to a repeated-measures ANOVA with three within-subjects factors: trial type (three levels: Remember Congruent vs Remember Incongruent vs Forgotten), time window, and electrode (three levels: $\mathrm{Fz}, \mathrm{Cz}, \mathrm{Pz}$ ). The factor time window is specified from the cluster analysis. Post hoc repeated-measures $t$ tests were performed to further characterize significant differences.

\section{Results}

\section{Behavioral findings}

Experiment 1

In Experiment 1, we sought to test the central hypothesis that events that are congruent with a semantic category are remembered more frequently and generate more semantically related intrusions (Lure words) than incongruent events. To test this possibility, for each encoding condition (Congruent vs Incongruent), the percentage of 'Old' responses for truly presented words (Trues) and Lures was calculated over the total number of test items of that category presented.

As expected, hit rates and lure rates were higher than chance for both conditions, both including all responses, and separately only including high-confidence responses (Table 2, all $p<$ $0.001)$. In line with the congruence effect, we found better recognition of true words at test for those words that were preceded by a congruent semantically related word cue during the encoding. However, lists encoded from the congruent condition elicited higher rates of memory illusions for lure words (Fig. 1a; Table 3). Indeed, we found significant main effects for test item type (True or Lure) $\left(F_{(1,30)}=104.82, p<0.001, \eta_{p}^{2}=0.78\right)$, as well as for congruence $\left(F_{(1,30)}=6.41, p=0.017, \eta_{\mathrm{p}}^{2}=0.18\right)$. We did not find a significant interaction between congruence and item type $(p=$ 0.626). Post hoc repeated-measures $t$ tests confirmed that there were more erroneous 'Old' responses to incongruent 'Lure' words than to unrelated 'New' words $\left(t_{(30)}=8.90, p<0.001\right.$, Cohen's $d=1.81$ ), indicating there was a significant amount of false recognition of 'Lure' words in both the congruent and incongruent conditions.

It could be still argued that the greater tendency to falsely recognize a lure word as if it had been presented during encoding could be partly explained by the degree of confidence and not by an inherent memory process engaged during the task. Thus, to contrast this possibility, we separately analyzed only the proportions of high-confidence 'Sure' responses during the recognition phase (Otten et al., 2006). Importantly, this analysis showed the same effects described above. We found significant main effects for item type $\left(F_{(1,30)}=153.71, p<0.001, \eta_{\mathrm{p}}^{2}=0.84\right)$, as well as for congruence $\left(F_{(1,30)}=7.46, p=0.010, \eta_{\mathrm{p}}^{2}=0.199\right)$. We did not find a significant interaction between congruence and item type $(p=0.262)$. Post hoc repeated-measures $t$ tests confirmed that there were more erroneous 'Sure-Old' responses to incongruent 'Lure' words than to unrelated 'New' words $\left(t_{(30)}=8.21, p<\right.$ 0.001 , Cohen's $d=1.80$ ).

To rule out the possibility of a different probability of remembering the first word of each sequence for the different congruency conditions, or any other possible word order $X$ congruency interaction, we ran a control experiment $(N=24)$ to gather the data of the memory responses for each word in order (Table 4). A 2 (congruence) $\times 4$ (word order) ANOVA was performed on the uncorrected total hit rates. As expected, there was a main effect of congruence $\left(F_{(1,23)}=36.53 ; p<0.001 ; u_{p}^{2}=0.614\right)$, and a main effect of word order $\left(F_{(3,69)}=6.83 ; p=0.001 ; u_{p}^{2}=0.229\right)$. Critically, there was no congruency $X$ word order interaction $\left(F_{(3,69)}=1.07 ; p=0.367 ; u_{p}^{2}=0.045\right)$. We analyzed the high confidence memory responses separately and found exactly the same results.

In sum, the results from Experiment 1 indicate that (1) the encoding of words that were congruent with a preactivated semantic network was better remembered than words preceded by an incongruent semantic context; and (2) the memory enhancement seen for the congruent condition was also accompanied by 
Table 2. Recognition memory data $\mathrm{I}^{a}$

\begin{tabular}{|c|c|c|c|c|c|c|c|c|}
\hline \multirow[b]{3}{*}{ Experiment } & \multicolumn{4}{|c|}{ Total ('sure' and unsure) } & \multicolumn{4}{|c|}{ High-confidence ('sure') } \\
\hline & \multicolumn{2}{|l|}{ True } & \multicolumn{2}{|l|}{ Related lure } & \multicolumn{2}{|l|}{ True } & \multicolumn{2}{|l|}{ Related lure } \\
\hline & Congruent & Incongruent & Congruent & Incongruent & Congruent & Incongruent & Congruent & Incongruent \\
\hline 1 & $0.77(0.01)$ & $0.74(0.02)$ & $0.71(0.02)$ & $0.68(0.02)$ & $0.89(0.01)$ & $0.86(0.01)$ & $0.82(0.02)$ & $0.77(0.02)$ \\
\hline 2 & $0.77(0.02)$ & $0.71(0.02)$ & $0.71(0.02)$ & $0.64(0.02)$ & $0.88(0.02)$ & $0.82(0.02)$ & $0.80(0.03)$ & $0.72(0.03)$ \\
\hline 3 & $0.78(0.03)$ & $0.78(0.03)$ & $0.70(0.03)$ & $0.70(0.04)$ & $0.91(0.02)$ & $0.90(0.02)$ & $0.76(0.05)$ & $0.76(0.05)$ \\
\hline 4 & $0.77(0.02)$ & $0.72(0.02)$ & - & - & $0.90(0.02)$ & $0.86(0.02)$ & - & - \\
\hline
\end{tabular}

a Data are mean (SEM) for congruent, incongruent, true, related lure, total responses collapsed across confidence levels, and high-confidence 'sure' responses. Values were obtained by comparing either true hit rates or related lure rates with unrelated false-alarms with the following formula: Response rate/(Response rate + Unrelated false alarm rate) (Urgolites et al., 2015). Single-sample $t$ test showed that each of the conditions was higher than chance ( $>0.50)$. In other words, subjects were able to distinguish both true and related lure words from unrelated new words (all $p<0.001$ ).

a greater tendency to falsely remember a semantically related word, never seen during encoding. Furthermore, these behavioral effects were observed, even in highly confident cases, thereby discarding the possibility that the disproportionate false memory effect in the congruent condition could be explained by familiarity rather than recollective processes (Yonelinas, 2001; Wixted and Mickes, 2010).

However, these findings alone cannot disambiguate whether the congruency effect could be explained by online encoding processes or, alternatively, whether they could be driven by offline memory processes (immediate poststimulus processes). Given that, in our study, participants were instructed to view the stimuli attentively and that they were asked to evaluate the congruency between the cue and the word list, it would be fair to assume that participants rapidly focused their attention to the representation of a gist immediately after encoding. The maintenance of a gistbased representation could ultimately boost participants' later memory performance to rely on a gist memory trace developed right after word income rather than on an online memory coding of the words. If this is the case, an interference task during poststimulus time period should minimize or even eliminate differences in memory performance between congruent and incongruent conditions in our Experiment 1, and this was the aim of Experiment 2.

\section{Experiment 2}

Overall, data from Experiment 2 replicated the behavioral effects observed in Experiment 1 (Fig. 1b; Table 3). Thus, there was a strong congruence effect for both 'True' and 'Lure' words. As expected, hit rates and lure rates were higher than chance for both conditions, both including all responses and separately only including high-confidence responses (Table 2; all $p<0.001$ ). We found significant main effects for the different types of items in the test $\left(F_{(1,20)}=68.32, p<0.001, \eta_{\mathrm{p}}^{2}=0.77\right)$, as well as for congruence $\left(F_{(1,20)}=30.95, p<0.001, \eta_{\mathrm{p}}^{2}=0.61\right)$. We also found a significant interaction between item type and congruence $\left(F_{(1,20)}=5.27, p=0.033, \eta_{\mathrm{p}}^{2}=0.21\right)$. However, there were no differences between interference conditions or an interaction with interference condition (all $p>0.17$ ), showing that the interference task did not modify the congruence effect when performed either before or after the classification judgment.

Post hoc repeated-measures $t$ tests confirmed that there were more correct 'Old' responses to congruent 'True' words than to incongruent 'True' words $\left(t_{(20)}=6.58, p<0.001\right.$, Cohen's $d=$ $2.39)$; more erroneous 'Old' responses to congruent 'Lure' words than to incongruent 'Lure' words $\left(t_{(20)}=4.25, p<0.001\right.$, Cohen's $d=1.07)$; and more erroneous 'Old' responses to incongruent 'Lure' words than to unrelated 'New' words $\left(t_{(20)}=7.86\right.$, $p<0.001$, Cohen's $d=1.12$ ).
Again, when we restricted the analysis to include only highconfidence 'Sure' responses, we found exactly the same effects as when including all trials independent of response confidence.

\section{Experiment 3}

The goal of Experiment 3 was to test the prediction that the memory effects seen in Experiments 1 and 2 were driven by an 'active' role of the participants in linking the word list to the semantic network previously activated by the cue.

As expected, hit rates and lure rates were higher than chance for both conditions, both including all responses and separately only including high-confidence responses (Table 2; all $p<$ $0.001)$. We found a significant main effect of item type $\left(F_{(1,14)}=\right.$ 31.00, $\left.p<0.001, \eta_{\mathrm{p}}^{2}=0.69\right)$. However, we did not find a main effect of congruence or an interaction (all $p>0.11$ ), showing that the congruence memory effect depended on the participants classifying words as congruent or incongruent (Fig. 1c; Table 3). As expected, post hoc repeated-measures $t$ tests collapsing congruent and incongruent conditions confirmed that there were more erroneous 'Old' responses to incongruent 'Lure' words than to unrelated 'New' words $\left(t_{(14)}=11.49, p<0.001\right.$, Cohen's $d=$ $2.81)$. Again, similar effects were found when including highconfidence 'Sure' responses in the analyses.

\section{Experiment 4}

To examine the extent to which the enhanced memory for congruent material derived from the need to encode very rapidly the sequence of 4 semantically related words, participants in Experiment 4 were requested to encode single words.

As expected, hit rates and lure rates were higher than chance for both conditions, both including all responses, and separately only including high-confidence responses (Table 2 , all $p<0.001$ ). We found a significant main effect of congruence in the test $\left(F_{(1,19)}=\right.$ 96.42, $p<0.001, \eta_{\mathrm{p}}^{2}=0.84$ ) (Table 3). Post hoc repeated-measures $t$ tests confirmed that there were more correct 'Old' responses to congruent 'True' words than to incongruent 'True' words $\left(t_{(19)}=9.82\right.$, $p<0.001$, Cohen's $d=1.66)$; and more correct 'Old' responses to incongruent 'True' words than to unrelated 'New' words $\left(t_{(19)}=\right.$ 14.31, $p<0.001$, Cohen's $d=2.69$ ).

When we restricted the analysis to include only high-confidence 'Sure' responses, we found the same effects. We found significant main effect of congruence in the test $\left(F_{(1,19)}=119.82, p<0.001\right.$, $\left.\eta_{\mathrm{p}}^{2}=0.86\right)$. Post hoc repeated-measures $t$ tests confirmed that there were more correct 'Sure-Old' responses to congruent 'True' words than to incongruent 'True' words $\left(t_{(19)}=10.95, p<0.001\right.$, Cohen's $d=1.41$ ); and more correct 'Sure-Old' responses to incongruent 'True' words than to unrelated 'New' words $\left(t_{(19)}=12.23, p<0.001\right.$, Cohen's $d=2.37$ ). 

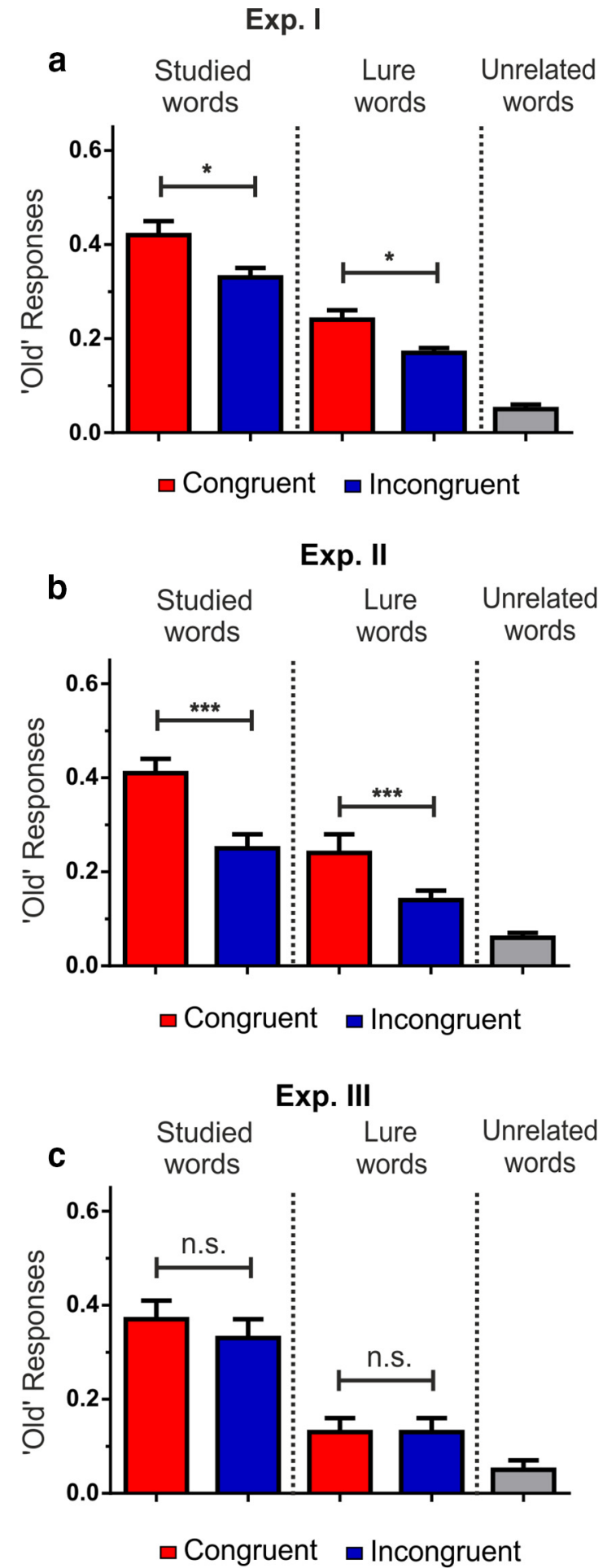

Figure 1. Behavioral results for Experiments 1-3. $\boldsymbol{a},{ }^{\prime}$ Old' response rate for each word type with responses for lure words as erroneously 'remembering' the word. We included in the figures only 'Sure' responses; total correct hit rate for 'True' congruent words was 0.62 and for 'True' incongruent words was 0.53 . b. Experiment 2. Participants solved arithmetic tasks after or before category judgment. c, Experiment 3 . With no category judgment. ${ }^{*} p<0.05$. ${ }^{* * *} p<$ 0.001. Error bars indicate SEM.

\section{ERP findings}

Experiment 1

Having shown that the encoding of events congruent with existing semantic knowledge produced a rapid online memory integration of the semantic information of the encoded words, we
Table 3. Recognition memory data II $^{a}$

\begin{tabular}{lllllll}
\hline \multirow{2}{*}{ Experiment } & \multicolumn{2}{l}{ Studied words } & & \multicolumn{2}{l}{ Lure words } & \\
\cline { 2 - 3 } & Congruent & Incongruent & & Congruent & Incongruent nn & False alarms \\
\hline 1 & $0.42(0.03)$ & $0.33(0.02)$ & & $0.24(0.02)$ & $0.17(0.02)$ & $0.05(0.01)$ \\
2 & $0.41(0.03)$ & $0.25(0.03)$ & & $0.24(0.04)$ & $0.14(0.02)$ & $0.06(0.02)$ \\
3 & $0.37(0.04)$ & $0.33(0.04)$ & & $0.13(0.03)$ & $0.13(0.03)$ & $0.05(0.03)$ \\
4 & $0.59(0.04)$ & $0.36(0.03)$ & - & - & $0.08(0.02)$ \\
\hline
\end{tabular}

${ }^{a}$ Data are mean (SEM). Recognition is shown by the mean proportion of sure old responses for studied words (True), semantically related lure words, and old responses to false alarms (unrelated new words), with responses for lure words as erroneously 'remembering' the word. The false alarms are not associated with any list and therefore are not separated by congruency. We show here only 'Sure' responses.

Table 4. Recognition memory data for each word: control experiment ${ }^{a}$

\begin{tabular}{lllllc}
\hline & Word 1 & Word 2 & Word 3 & Word 4 & False alarms \\
\hline Congruent & $0.78(0.03)$ & $0.80(0.02)$ & $0.77(0.03)$ & $0.87(0.02)$ & $0.24(0.05)^{b}$ \\
Incongruent & $0.66(0.04)$ & $0.64(0.05)$ & $0.64(0.04)$ & $0.69(0.04)$ & - \\
\hline
\end{tabular}

${ }^{a}$ Data are mean (SEM) of the total uncorrected hit rates for each studied word in order of apparition in their respective sequences. Data are shown for the control experiment $(N=24)$. Both low- and high-confidence responses are included.

${ }^{b}$ Unrelated false alarms are not congruent or incongruent (see Materials and Methods). Here total responses collapsed across high- and low-confidence are shown.

asked whether this process could be observed at the neural response level. In addition, this would allow pinpointing this process in time. Because we aimed at identifying a very rapid memory coding mechanism, EEG data were recorded while participants participated in Experiment 1.

Electrophysiological responses to this experiment are shown in Figure 2. The raster diagram illustrates significant ERP differences between remembered lists and forgotten lists (Fig. 2a) independent of whether word lists were congruent or incongruent during encoding. The maximum cluster-level mass procedure returned two significant very broadly distributed clusters. The first lasted from 370 to $680 \mathrm{~ms}$, and the second lasted from 770 to $1170 \mathrm{~ms}$. We performed the following ANOVA using these two separate time windows.

Thus, the mean amplitude values were submitted to a repeatedmeasures ANOVA with three within-subjects factors: trial type (three levels: Remember Congruent vs Remember Incongruent vs Forgotten), time window (two levels: Early vs Late), and electrode (three levels: $\mathrm{Fz}, \mathrm{Cz}, \mathrm{Pz}$ ). The ANOVA returned a main effect of electrode $\left(F_{(2,60)}=4,22, p=0.044, \eta_{\mathrm{p}}^{2}=0.12\right)$, a main effect of trial type $\left(F_{(2,60)}=7.06, p=0.003, \eta_{p}^{2}=0.19\right)$, a main effect of time window $\left(F_{(1,30)}=8.51, p=0.007, \eta_{p}^{2}=0.22\right)$, a time window $\times$ electrode interaction $\left(F_{(2,60)}=4.71, p=0.030, \eta_{\mathrm{p}}^{2}=0.14\right)$, and a time window $\times$ trial type interaction $\left(F_{(2,60)}=27.84, p<0.001\right.$, $\left.\eta_{\mathrm{p}}^{2}=0.48\right)$. Post hoc repeated-measures $t$ tests were run on the $\mathrm{Fz}$ electrode to decompose the time window $\times$ trial type interaction. The post hoc analysis was centered on changes in the Fz electrode, possibly reflecting the role of the frontal regions in the detection of congruency and subsequent modulation of encoding (van Kesteren et al., 2012), and because there was no trial type $\times$ time window $\times$ electrode interaction $(p=0.415)$. In the early time window, Congruent Remembered trials significantly differed from Incongruent Remembered trials $\left(t_{(31)}=2.67, p=0.001\right.$, Cohen's $d=0.42$, and from Forgotten trials $\left(t_{(31)}=3.64, p<0.001\right.$, Cohen's $\left.d=0.52\right)$. However, there were no significant differences between Incongruent Remembered trials and Forgotten trials $(p=0.737)$. In the late time window, both Congruent Remembered trials $\left(t_{(31)}=3.31, p=\right.$ 0.002 , Cohen's $d=0.47)$ and Incongruent Remembered trials $\left(t_{(31)}=2.83, p=0.008\right.$, Cohen's $\left.d=0.48\right)$ differed from Forgotten trials. However, there were no significant differences between Congruent and Incongruent Remembered trials $(p=0.616)$. As can be 


\section{a}
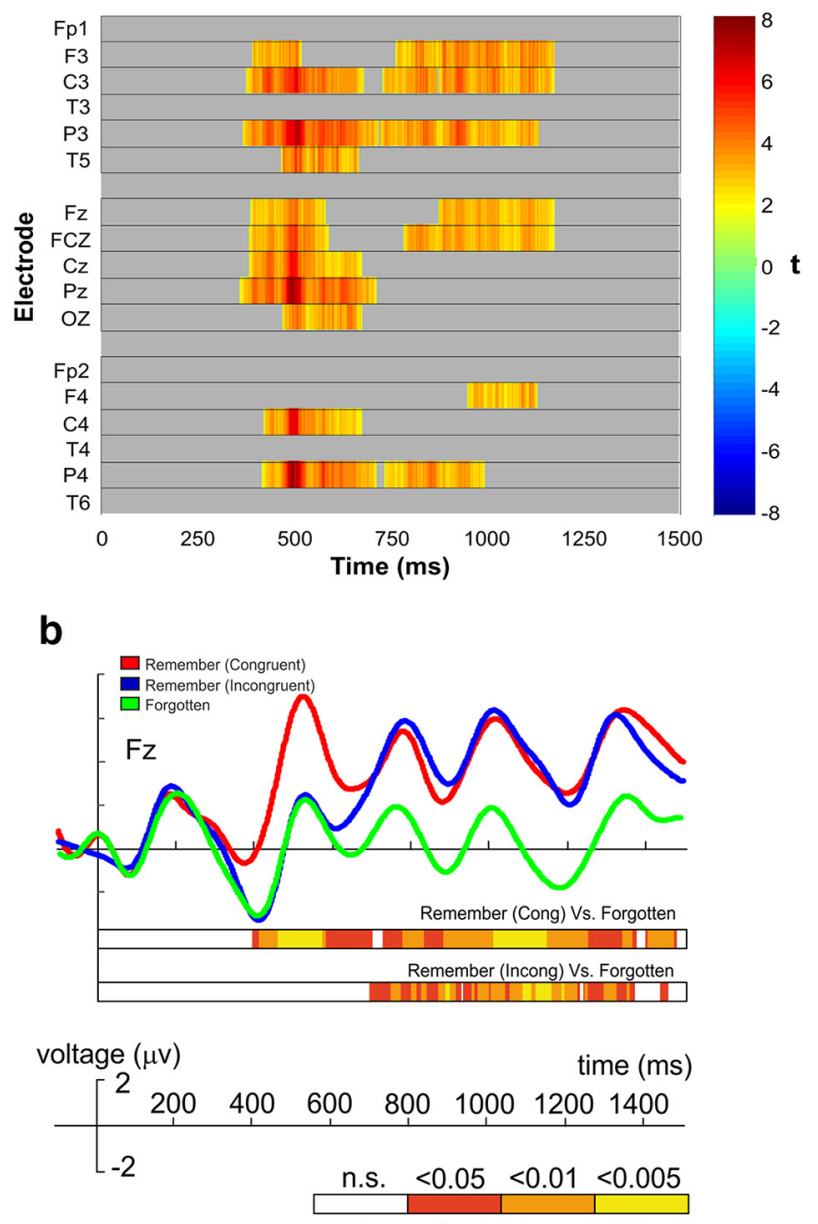

p-values of point-by-point t-tests

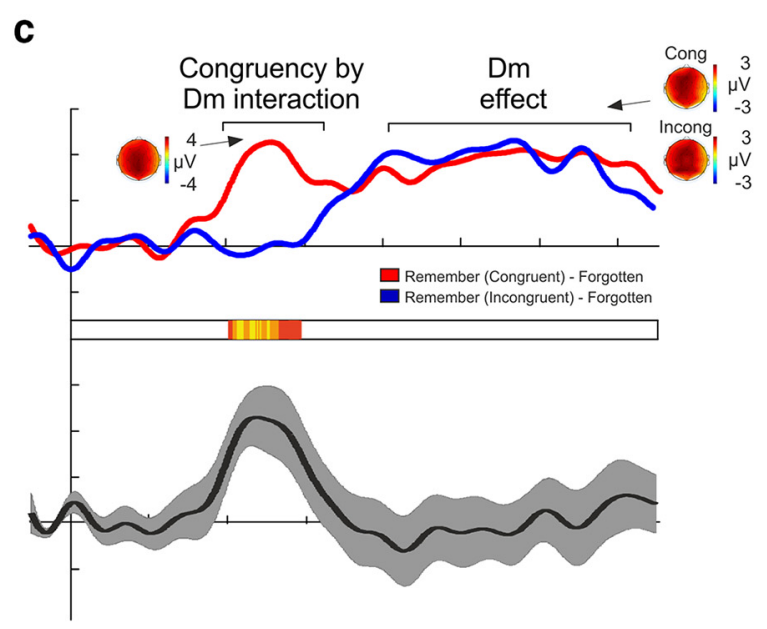

Figure 2. ERPs for Experiment 1. $\boldsymbol{a}$, Two-tailed repeated-measures cluster mass permutation test contrasting ERPs for remembered and forgotten lists. $\boldsymbol{b}$, Grand-average ERP waveforms (Fz electrode) elicited during encoding of congruent and incongruent subsequently remembered word lists (minimum 2 words remembered with certainty) and during the encoding of word lists subsequently forgotten (including congruent and incongruent word lists). Point-by-point paired-sample Student's $t$ test results are depicted in a color code indicating three ranges of significant $p$ values, comparing 'Congruent Remembered' versus 'Forgotten' and 'Incongruent Remembered' versus 'Forgotten.' $c$, Grand-average ERPs elicited for forgotten word lists were subtracted from ERPs elicited for word lists remembered under both conditions. Bottom, Point-by-point $p$ values resulting from contrasting both ERPs. The grand-average difference ERP ( \pm SEM) waveform from both ERPs is also plotted. seen in Figure $2 b, c$, there was a significant difference due to subsequent memory effect in the congruent condition alone in the early time window. In the late time window, there was a significant difference due to memory effect in both the congruent and the incongruent conditions.

Yet, and even the number of congruent and incongruent trials in the forgotten condition were equalized in number, it could still be argued that each condition may have had a different weighting in the resulting ERP. To control for this possibility, we ran a repeated-measures ANOVA including as within-subject factors congruence (congruent, incongruent), memorability (remembered, forgotten), and electrode $(\mathrm{Fz}, \mathrm{Cz}$, and $\mathrm{Pz}$ ) for ERP data from each of the two time windows described previously. The results of these ANOVAs confirmed our previous findings by revealing a significant main effect of congruence $\left(F_{(1,30)}=4.95\right.$, $\left.p=0.034, \eta_{\mathrm{p}}^{2}=0.14\right)$ and a congruence $\times$ memorability interaction $\left(F_{(1,30)}=5.37, p=0.027, \eta_{\mathrm{p}}^{2}=0.15\right)$, in the early time window, as well as a main significant effect of memorability $\left(F_{(1,30)}=19.52, p<0.001, \eta_{\mathrm{p}}^{2}=0.39\right)$ but not a significant congruence $\times$ memorability interaction $\left(F_{(1,30)}=1.56, p=0.22\right.$, $\left.\eta_{\mathrm{p}}^{2}=0.05\right)$ in ERP data from the late time window.

The ERP findings from Experiment 1 revealed the emergence of a neural response associated with successful memory encoding that preceded the classical DM ERP effect. This positive ERP rose over frontocentral scalp regions and appeared only during the encoding of congruent words. Critically, subsequent neural responses classically associated with successful encoding (i.e., DM effect) did not differ between the two encoding conditions, thereby suggesting that the memory enhancement for congruent words cannot be explained by greater engagement of long-term memory mechanisms to these events. Instead, we reason that an accelerated process of memory integration took place when the existing semantic network and the online event input matched during encoding.

\section{Experiment 4}

Electrophysiological responses for the words are shown in Figure 3. The results confirmed what we found in Experiment 1. The raster diagram illustrates significant differences between remembered lists and forgotten lists (Fig. 3a) independent of whether word lists were congruent or incongruent during encoding. The maximum cluster-level mass procedure returned two significant clusters. The first lasted from 396 to $672 \mathrm{~ms}$, and the second lasted from 724 to $1368 \mathrm{~ms}$. For the ANOVA, we used these two time windows. Thus, the mean amplitude values were submitted to a repeated-measures ANOVA with three within-subjects factors: trial type (three levels: Remember Congruent vs Remember Incongruent vs Forgotten), time window (two levels: Early vs Late), and electrode (three levels: $\mathrm{Fz}, \mathrm{Cz}, \mathrm{Pz}$ ). The ANOVA returned a main effect of electrode $\left(F_{(2,38)}=15.98, p<0.001, \eta_{\mathrm{p}}^{2}=0.46\right)$, a main effect of trial type $\left(F_{(2,38)}=13.25, p<0.001, \eta_{\mathrm{p}}^{2}=0.41\right)$, and a time window $\times$ trial type interaction $\left(F_{(2,38)}=20.11, p<\right.$ $\left.0.001, \eta_{\mathrm{p}}^{2}=0.51\right)$. Post hoc two-tailed $t$ tests were run on the Fz electrode to decompose the time window $\times$ trial type interaction. The results replicated what we found in Experiment 1. In the early time window, there were significant differences between Congruent Remembered trials and Incongruent Remembered trials $\left(_{(19)}=3.81, p=0.001\right.$, Cohen's $\left.d=0.45\right)$, and between Congruent Remembered trials and Forgotten trials $\left(t_{(19)}=4.45, p<\right.$ 0.001 , Cohen's $d=0.61$ ); however, there were no significant differences between Incongruent Remembered trials and Forgotten trials $(p=0.393)$. In the late time window, there were significant differences between Congruent Remembered trials and 
Forgotten trials $\left(t_{(19)}=3.64, p=0.002\right.$, Cohen's $d=0.72$ ), and between Incongruent Remembered trials and Forgotten trials $\left(t_{(19)}=2.13, p=0.046\right.$, Cohen's $d=$ $0.44)$; however, there were no significant differences between Congruent Remembered trials and Incongruent Remembered trials $(p=0.296)$. As can be seen in Figure $3 b, c$, there was a significant difference due to subsequent memory effect in the congruent condition alone in the early time window. In the late time window, there was a significant difference due to memory effect in both the congruent and the incongruent conditions.

\section{Discussion}

Here we showed that congruent readily available schematic information, preactivated by a semantic category cue, allowed for more successful encoding by accelerating the onset of neural mechanisms underlying the integration into memory of semantic information together with the input of an event. We found an early electrophysiological DM effect in the congruent condition only, as well as a later general DM effect in both the congruent and incongruent conditions. Thus, these findings reveal encoding-dependent brain mechanisms that account for a rapid integration of current and existing congruent semantic information and its consequences at long-term memory.

The rate at which we can semantically integrate presented information may define our capacity not only to remember but also to understand encoded events (Long et al., 2008). Our results may help explain how humans can efficiently encode into memory rapid streams of events. The early congruence DM effect and the later DM effect we found in both conditions might correspond to the neural activity found in an earlier intracortical study (Fernández et al., 1999). Considering the timing of the effects found here, however, the integration of semantic information with congruent events might have taken place after initial semantic access, associated with the N400 effect (Kutas and Federmeier, 2011), and before long-term coding (Paller and Wagner, 2002).

Our results support the idea that congruent-memory effects are driven by semantic associations (Staresina et al., 2009; Bein et al., 2015), and suggest that such semantic information drives the tendency for subsequent false memories. Thus, our results suggest congruent events are integrated together with semantic associations before becoming long-term memory traces.

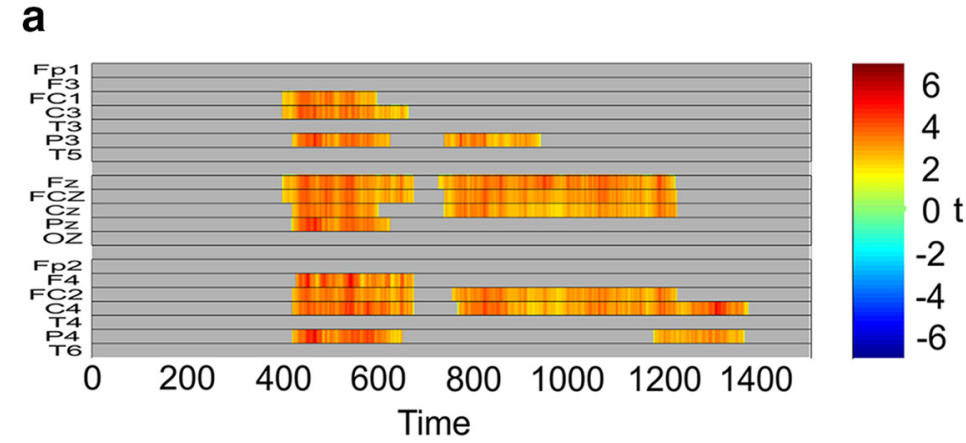

b
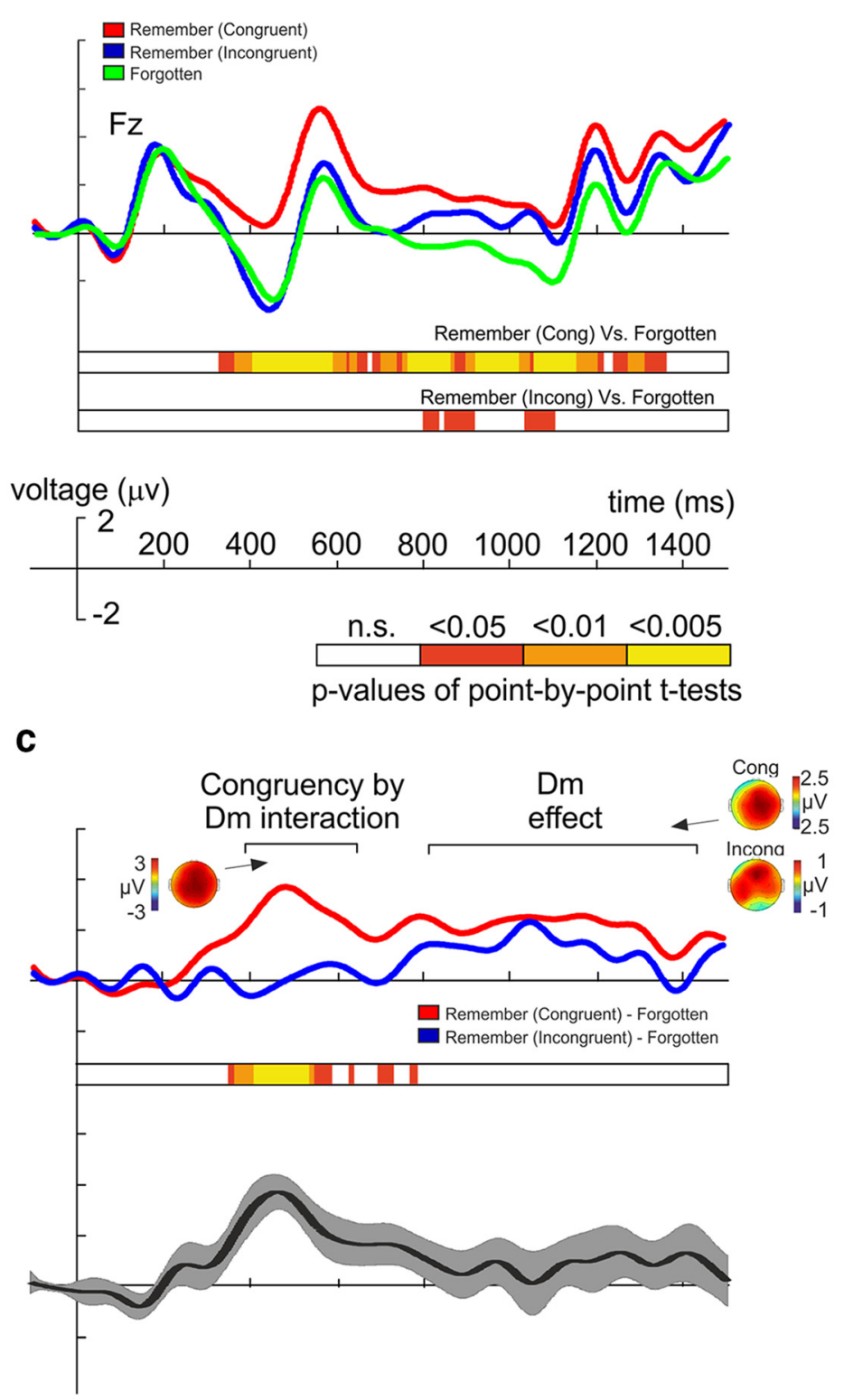

Figure 3. ERPs for Experiment 4. a, Two-tailed repeated-measures cluster mass permutation test contrasting ERPs for remembered and forgotten words. $\boldsymbol{b}$, Grand-average ERP waveforms (Fz electrode) elicited during encoding of congruent and incongruent subsequently remembered words and during the encoding of words subsequently forgotten (including congruent and incongruent words). Point-by-point paired-sample Student's $t$ test results are depicted in a color code indicating three ranges of significant $p$ values, comparing 'Congruent Remembered' versus 'Forgotten' and 'Incongruent Remembered' versus 'Forgotten.' c, Grand-average ERPs elicited for forgotten words were subtracted from ERPs elicited for words remembered under both conditions. Bottom, Point-by-point $p$ values resulting from contrasting both ERPs. The grand-average difference ERP ( \pm SEM) waveform from both ERPs is also plotted. 
Although Experiment 1 was limited by the small number of trials per condition (mean of $\sim 14$ ), Experiment 4 had a much higher number of trials (mean of $\sim 57$ ) per condition and replicated the results. The selection criteria for remembered sequences in Experiment 1 also allowed for certain ambiguities in the interpretation of the results; Experiment 4 corrected for this. In Experiment 4, the two significant clusters were similar to those we found in Experiment 1, although a little less broadly distributed. The results thus confirmed that the neural effects occur with a similar timing independently of whether complex sequences of words or single words are requested for encoding.

In Experiment 3, in which participants did not engage in deep encoding, there were no behavioral differences between conditions. These results highlight the importance of participants engaging in an active search for meaning-based congruence between the words and the previous cue, consistent with the idea that processing goals influence encoding (Paller and Wagner, 2002). Our results are thus related to the level-of-processing effect (Craik and Lockhart, 1972), with participants' performance depending on the type of processing they are instructed to engage in (Craik and Tulving, 1975), deep processing being necessary for the memory-related congruence effects. Several deep encoding tasks cause memory improvements (Craik and Lockhart, 1972; Craik and Tulving, 1975; Otten and Rugg, 2001a, b; Otten et al., 2001; Hanslmayr et al., 2009; Fellner et al., 2013), they all involve meaning-related processing tasks and either are associated with a broader area of SMEs (Baker et al., 2001; Otten et al., 2001) or engage different brain areas compared with shallow encoding tasks (Otten and Rugg, 2001a). Deep processing-related SMEs have been detected shortly after word onset (Otten and Rugg, 2001b; Hanslmayr et al., 2009; Fellner et al., 2013). Our observations thus relate to the literature on deep processing SMEs and suggest that further critical differences exist between the deep processing of congruent and incongruent stimuli. Although we do not have EEG data for Experiment 3, we speculate that the memory-related congruency effect would not be observed on a neural level for this paradigm, or would be significantly reduced in amplitude. This would be consistent with a direct causal link between the neural effect and the behavioral effect in memory performance.

In Experiment 1, the fact that we found 1 congruence-related SME and not 4 independent ones ( 1 for each word) suggests that the 4 words are encoded together, perhaps in a memory trace that wraps up the semantic cue together with the 4 words in the following sequence. The results from Experiment 2, together with the timing of the SMEs, are consistent with the idea that the critical neural processes for the memory-related congruence effect take place in this paradigm during the online encoding of the words (i.e., during the first second of the word sequence presentation). Such disambiguation between online memory coding and offline memory maintenance suggests that the consequences of encoding novel information in a semantic congruent context were supported by successful memory processing that was initiated very rapidly during encoding and cannot be accounted by early memory maintenance and subsequent elaboration of the input words.

Another interesting line of research would be to investigate how and under which circumstances processes of mismatch detection and interference may interact with the kind of memoryrelated congruence effect we elicited with this paradigm. Previous studies have detected distinct parallel memory signatures in the hippocampus in humans (Duncan et al., 2009) and in the perirhinal cortex in monkeys (Miller and Desimone, 1994). These stud- ies describe on one hand an automatic mismatch detection mechanism (Kumaran and Maguire, 2006, 2007; Duncan et al., 2009). Substantial evidence shows how such a mismatch signal is followed by a cascade of neural responses that lead to greater attention and memory for novel stimuli (Ranganath and Rainer, 2003). A recent model of schema-dependent encoding posits incongruence detection of this kind is related to an increase in nonsemantic MTL-dependent encoding of arbitrary associations (van Kesteren et al., 2012). In line with our results, the memory signatures for matching stimuli have been found to depend on internally generated goals and thus are not automatic but rather actively controlled (Miller and Desimone, 1994; Duncan et al., 2009).

How processes of familiarity and recollection contributed to our results and, specifically, to the congruence-related memory effect we found evidence for, is a very interesting question. True memories in the DRM paradigm have been associated principally to recollective processes (Kim and Cabeza, 2007a; Fuentemilla et al., 2009), whereas false memories have been associated with familiarity processes (Kim and Cabeza, 2007b). It is possible, however, for individuals to use familiarity also for true items in recognition paradigms (Edelstyn et al., 2007). In contrast, false memories putatively are caused either by familiarity due to relatedness with true memories or constructive processes that lead to erroneous recollections. We found the congruence-related memory effect increased both true and false memories. A parsimonious explanation could be, therefore, that this effect is due mainly to a boost in familiarity-related processes. However, some studies have found evidence for congruence-related memory benefits for episodic associations between places and faces (Atienza et al., 2011; Crespo-Garcia et al., 2012). Furthermore, false memories in the DRM paradigm also emerge in free recall tests, and often include remember judgments in recognition tests (Gallo, 2010). In some unpublished data of ours, we have found that congruence increased the proportion of remember judgments for both true and false memories. This complicates a direct interpretation of the remember/know distinction in the DRM paradigm as there is the possibility of false memories being accompanied by a false sense of recollection due to constructive memory processes. Indeed, real-life false memories are often accompanied by the feeling that they were actually experienced (Loftus and Bernstein, 2005). Furthermore, although there exists a neural dissociation between true and false memories (Kim and Cabeza, 2007a, b; Fuentemilla et al., 2009), there is still considerable overlap in the neural bases (Dennis et al., 2015). As such, it is not yet entirely clear whether the congruence-related memory effect is supported mainly by familiarity, recollection, or a combination of the two.

The importance of prior knowledge in memory has been demonstrated in a wide variety of domains (Chase and Simon, 1973; Voss et al., 1980; McKeithen et al., 1981; Alba and Hasher, 1983; Tse et al., 2007; Long et al., 2008). Furthermore, the congruence effect has been repeatedly demonstrated in paradigms using a wide variety of stimuli (Staresina et al., 2009; van Kesteren et al., 2010a; Atienza et al., 2011; Naghavi et al., 2011). This suggests that the present results might correspond to a general memory mechanism.

Given that the time interval between encoding and the subsequent test $(\sim 10 \mathrm{~min})$ was too short for long-term consolidation processes to act upon the memories, the behavioral effects shown here are thus specifically due to the encoding component of the schema effect. This supports the idea that encoding processes play an important role in the schema effect (Staresina et al., 2009; van Kesteren et al., 2010b, 2012, 2014; Tse et al., 2011). The 
longer-term consolidation component might add upon the observed congruence-related effect, further amplifying the behavioral memory performance differences we observed over time. According to a recent model (van Kesteren et al., 2012), congruent events are more likely to be subsequently consolidated over longer time intervals through the repeated reactivation by offline replay or reexposure to elements related to the congruent schema, thus causing repeated strong activation spreads to the congruent event. The congruence-related memory processes we observed might represent an initial step in the type of accelerated schema-dependent consolidation described in lesion studies with rats (Tse et al., 2007, 2011).

Recent systems consolidation accounts (Winocur et al., 2007; Winocur and Moscovitch, 2011; Nadel et al., 2012) describe how initial memory traces are subsequently transformed and integrated into semantic information networks. Congruency may guide this selective transformation process (van Kesteren et al., 2012). Interestingly, animal studies suggest that congruency can accelerate, up to the rate of single trial learning, integration of new information into long-term cortical memory stores (Tse et al., 2007; Cohen et al., 2015). Congruence between prior semantic or schema knowledge and current events could promote this special type of rapid integration and consolidation (Dudai et al., 2015).

\section{References}

Alba JW, Hasher L (1983) Is memory schematic? Psychol Bull 93:203-231. CrossRef

Atienza M, Crespo-Garcia M, Cantero JL (2011) Semantic congruence enhances memory of episodic associations: role of theta oscillations. J Cogn Neurosci 23:75-90. CrossRef Medline

Baker JT, Sanders AL, Maccotta L, Buckner RL (2001) Neural correlates of verbal memory encoding during semantic and structural processing tasks. Neuroreport 12:1251-1256. CrossRef Medline

Bartlett FC, Burt C (1933) Remembering: a study in experimental and social psychology. Br J Educ Psychol 3:187-192. CrossRef

Battig WF, Montague WE (1969) Category norms of verbal items in 56 categories: a replication and extension of the Connecticut category norms. J Exp Psychol 80:1-46. CrossRef

Bein O, Livneh N, Reggev N, Gilead M, Goshen-Gottstein Y, Maril A (2015) Delineating the effect of semantic congruency on episodic memory: the role of integration and relatedness. PLoS One 10:e0115624. CrossRef Medline

Ben-Yakov A, Dudai Y (2011) Constructing realistic engrams: poststimulus activity of hippocampus and dorsal striatum predicts subsequent episodic memory. J Neurosci 31:9032-9042. CrossRef Medline

Ben-Yakov A, Eshel N, Dudai Y (2013) Hippocampal immediate poststimulus activity in the encoding of consecutive naturalistic episodes. J Exp Psychol Gen 142:1255-1263. CrossRef Medline

Bullmore ET, Suckling J, Overmeyer S, Rabe-Hesketh S, Taylor E, Brammer MJ (1999) Global, voxel, and cluster tests, by theory and permutation, for a difference between two groups of structural MR images of the brain. IEEE Trans Med Imaging 18:32-42. CrossRef Medline

Chase WG, Simon HA (1973) Perception in chess. Cognit Psychol 4:55-81. CrossRef

Cohen N, Pell L, Edelson MG, Ben-Yakov A, Pine A, Dudai Y (2015) Periencoding predictors of memory encoding and consolidation. Neurosci Biobehav Rev 50:128-142. CrossRef Medline

Craik FI, Lockhart RS (1972) Levels of processing: a framework for memory research. J Verbal Learn Verbal Behav 11:671-684. CrossRef

Craik FI, Tulving E (1975) Depth of processing and the retention of words in episodic memory. J Exp Psychol Gen 104:268-294. CrossRef

Crespo-Garcia M, Cantero JL, Atienza M (2012) Effects of semantic relatedness on age-related associative memory deficits: the role of theta oscillations. Neuroimage 61:1235-1248. CrossRef Medline

Dennis NA, Bowman CR, Turney IC (2015) Functional neuroimaging of false memories. In: The Wiley handbook on the cognitive neuroscience of memory (Addis DR, Barense M, Duarte A, eds), pp 150-171. New York: Wiley.
Dudai Y, Karni A, Born J (2015) The consolidation and transformation of memory. Neuron 88:20-32. CrossRef Medline

Duncan K, Curtis C, Davachi L (2009) Distinct memory signatures in the hippocampus: intentional states distinguish match and mismatch enhancement signals. J Neurosci 29:131-139. CrossRef Medline

Edelstyn NM, Mayes AR, Condon L, Tunnicliffe M, Ellis SJ (2007) Recognition, recollection, familiarity and executive function in medicated patients with moderate Parkinson's disease. J Neuropsychol 1:131-147. CrossRef Medline

Fellner MC, Bäuml KH, Hanslmayr S (2013) Brain oscillatory subsequent memory effects differ in power and long-range synchronization between semantic and survival processing. Neuroimage 79:361-370. CrossRef Medline

Fernández G, Effern A, Grunwald T, Pezer N, Lehnertz K, Dümpelmann M, Van Roost D, Elger CE (1999) Real-time tracking of memory formation in the human rhinal cortex and hippocampus. Science 285:1582-1585. CrossRef Medline

Fernández G, Klaver P, Fell J, Grunwald T, Elger CE (2002) Human declarative memory formation: segregating rhinal and hippocampal contributions. Hippocampus 12:514-519. CrossRef Medline

Fuentemilla L, Càmara E, Münte TF, Krämer UM, Cunillera T, MarcoPallarés J, Tempelmann C, Rodriguez-Fornells A (2009) Individual differences in true and false memory retrieval are related to white matter brain microstructure. J Neurosci 29:8698-8703. CrossRef Medline

Gallo DA (2010) False memories and fantastic beliefs: 15 years of the DRM illusion. Mem Cognit 38:833-848. CrossRef Medline

Goikoetxea E (2000) Frecuencia de producción de las respuestas a 52 categorías verbales en niños de primaria. Psicológica 21:61-89.

Groppe DM, Urbach TP, Kutas M (2011) Mass univariate analysis of eventrelated brain potentials/fields: I. A critical tutorial review. Psychophysiology 48:1711-1725. CrossRef Medline

Hanslmayr S, Spitzer B, Bäuml KH (2009) Brain oscillations dissociate between semantic and nonsemantic encoding of episodic memories. Cereb Cortex 19:1631-1640. CrossRef Medline

Johnson R (1995) Event-related potential insights into the neurobiology of memory systems. Handb Neuropsychol 10:135-163.

Kim H (2011) Neural activity that predicts subsequent memory and forgetting: a meta-analysis of 74 fMRI studies. Neuroimage 54:2446-2461. CrossRef Medline

Kim H, Cabeza R (2007a) Trusting our memories: dissociating the neural correlates of confidence in veridical versus illusory memories. J Neurosci 27:12190-12197. CrossRef Medline

Kim H, Cabeza R (2007b) Differential contributions of prefrontal, medial temporal, and sensory-perceptual regions to true and false memory formation. Cereb Cortex 17:2143-2150. CrossRef Medline

Kumaran D, Maguire EA (2006) An unexpected sequence of events: mismatch detection in the human hippocampus. PLoS Biol 4:e424. CrossRef Medline

Kumaran D, Maguire EA (2007) Match-mismatch processes underlie human hippocampal responses to associative novelty. J Neurosci 27:85178524. CrossRef Medline

Kutas M, Federmeier KD (2011) Thirty years and counting: finding meaning in the N400 component of the event-related brain potential (ERP). Annu Rev Psychol 62:621-647. CrossRef Medline

Loftus EF, Bernstein DM (2005) Rich false memories: the royal road to success. In: Experimental cognitive psychology and its applications: decade of behavior, pp 101-113. Washington, DC: American Psychological Association.

Long DL, Prat C, Johns C, Morris P, Jonathan E (2008) The importance of knowledge in vivid text memory: an individual-differences investigation of recollection and familiarity. Psychon Bull Rev 15:604-609. CrossRef Medline

Marco-Pallares J, Cucurell D, Cunillera T, García R, Andrés-Pueyo A, Münte TF, Rodríguez-Fornells A (2008) Human oscillatory activity associated with reward processing in a gambling task. Neuropsychologia 46:241248. CrossRef Medline

McKeithen KB, Reitman JS, Rueter HH, Hirtle SC (1981) Knowledge organization and skill differences in computer programmers. Cognit Psychol 13:307-325. CrossRef

Miller EK, Desimone R (1994) Parallel neuronal mechanisms for shortterm memory. Science 263:520-522. CrossRef Medline

Nadel L, Hupbach A, Gomez R, Newman-Smith K (2012) Memory forma- 
tion, consolidation and transformation. Neurosci Biobehav Rev 36:16401645. CrossRef Medline

Naghavi HR, Eriksson J, Larsson A, Nyberg L (2011) Cortical regions underlying successful encoding of semantically congruent and incongruent associations between common auditory and visual objects. Neurosci Lett 505:191-195. CrossRef Medline

Otten LJ, Rugg MD (2001a) Task-dependency of the neural correlates of episodic encoding as measured by fMRI. Cereb Cortex 11:1150-1160. CrossRef Medline

Otten LJ, Rugg MD (2001b) Electrophysiological correlates of memory encoding are task-dependent. Brain Res Cogn Brain Res 12:11-18. CrossRef Medline

Otten LJ, Henson RN, Rugg MD (2001) Depth of processing effects on neural correlates of memory encoding: relationship between findings from across- and within-task comparisons. Brain J Neurol 124:399-412. CrossRef Medline

Otten LJ, Quayle AH, Akram S, Ditewig TA, Rugg MD (2006) Brain activity before an event predicts later recollection. Nat Neurosci 9:489-491. CrossRef Medline

Paller KA, Gross M (1998) Brain potentials associated with perceptual priming vs explicit remembering during the repetition of visual wordform. Neuropsychologia 36:559-571. CrossRef Medline

Paller KA, Wagner AD (2002) Observing the transformation of experience into memory. Trends Cogn Sci 6:93-102. CrossRef Medline

Ranganath C, Rainer G (2003) Neural mechanisms for detecting and remembering novel events. Nat Rev Neurosci 4:193-202. CrossRef Medline

Roediger HL, McDermott KB (1995) Creating false memories: remembering words not presented in lists. J Exp Psychol Learn Mem Cogn 21:803814. CrossRef

Rugg MD, Coles MG (1996) Electrophysiology of mind: event-related brain potentials and cognition. Oxford: Oxford UP.

Sanquist TF, Rohrbaugh J, Syndulko K, Lindsley DB (1980) An eventrelated potential analysis of coding processes in human memory. Prog Brain Res 54:655-660. CrossRef Medline

Staresina BP, Gray JC, Davachi L (2009) Event congruency enhances episodic memory encoding through semantic elaboration and relational binding. Cereb Cortex 19:1198-1207. CrossRef Medline

Sy JL, Elliott JC, Giesbrecht B (2013) Post-perceptual processing during the attentional blink is modulated by inter-trial task expectancies. Front Hum Neurosci 7:627. CrossRef Medline

Tambini A, Davachi L (2013) Persistence of hippocampal multivoxel patterns into postencoding rest is related to memory. Proc Natl Acad Sci U S A 110:19591-19596. CrossRef Medline

Tse D, Langston RF, Kakeyama M, Bethus I, Spooner PA, Wood ER, Witter MP, Morris RG (2007) Schemas and memory consolidation. Science 316:76-82. CrossRef Medline

Tse D, Takeuchi T, Kakeyama M, Kajii Y, Okuno H, Tohyama C, Bito H,
Morris RG (2011) Schema-dependent gene activation and memory encoding in neocortex. Science 333:891-895. CrossRef Medline

Tulving E (2002) Episodic memory: from mind to brain. Annu Rev Psychol 53:1-25. CrossRef Medline

Tulving E, Pearlstone Z (1966) Availability versus accessibility of information in memory for words. J Verbal Learn Verbal Behav 5:381-391. CrossRef

Urgolites ZJ, Smith CN, Squire LR (2015) True and false memories, parietal cortex, and confidence judgments. Learn Mem 22:557-562. CrossRef Medline

van Kesteren MT, Fernández G, Norris DG, Hermans EJ (2010a) Persistent schema-dependent hippocampal-neocortical connectivity during memory encoding and postencoding rest in humans. Proc Natl Acad Sci U S A 107:7550-7555. CrossRef Medline

van Kesteren MT, Rijpkema M, Ruiter DJ, Fernández G (2010b) Retrieval of associative information congruent with prior knowledge is related to increased medial prefrontal activity and connectivity. J Neurosci 30:15888 15894. CrossRef Medline

van Kesteren MT, Ruiter DJ, Fernández G, Henson RN (2012) How schema and novelty augment memory formation. Trends Neurosci 35:211-219. CrossRef Medline

van Kesteren MT, Rijpkema M, Ruiter DJ, Morris RG, Fernández G (2014) Building on prior knowledge: schema-dependent encoding processes relate to academic performance. J Cogn Neurosci 26:2250-2261. CrossRef Medline

Vilà-Balló A, Cunillera T, Rostan C, Hdez-Lafuente P, Fuentemilla L, Rodríguez-Fornells A (2015) Neurophysiological correlates of cognitive flexibility and feedback processing in violent juvenile offenders. Brain Res 1610:98-109. CrossRef Medline

Voss JF, Vesonder GT, Spilich GJ (1980) Text generation and recall by highknowledge and low-knowledge individuals. J Verbal Learn Verbal Behav 19:651-667. CrossRef

Winocur G, Moscovitch M (2011) Memory transformation and systems consolidation. J Int Neuropsychol Soc 17:766-780. CrossRef Medline

Winocur G, Moscovitch M, Sekeres M (2007) Memory consolidation or transformation: context manipulation and hippocampal representations of memory. Nat Neurosci 10:555-557. CrossRef Medline

Wixted JT, Mickes L (2010) A continuous dual-process model of remember/know judgments. Psychol Rev 117:1025-1054. CrossRef Medline

Woodruff CC, Hayama HR, Rugg MD (2006) Electrophysiological dissociation of the neural correlates of recollection and familiarity. Brain Res 1100:125-135. CrossRef Medline

Yonelinas AP (2001) Consciousness, control, and confidence: the 3 Cs of recognition memory. J Exp Psychol Gen 130:361-379. CrossRef Medline

Yoon C, Feinberg F, Hu P, Gutchess AH, Hedden T, Chen HY, Jing Q, Cui Y, Park DC (2004) Category norms as a function of culture and age: comparisons of item responses to 105 categories by american and chinese adults. Psychol Aging 19:379-393. CrossRef Medline 